Int. J. Electrochem. Sci., 16 (2021) Article ID: 210430

International Journal of

ELECTROCHEMICAL

SCIENCE

$\underline{\text { www.electrochemsci.org }}$

\title{
The Influence of Temperature and Dissolved Oxygen on the Electrochemical Properties of Three Al-Zn-In Series Sacrificial Anodes
}

\author{
Xinwei Zhang ${ }^{1,2}$, Cuiwei Du ${ }^{1,2,3, *}$, Zhiyong Liu $^{1,2, *}$, Kai Liu $^{4}$ \\ ${ }^{1}$ Institute for Advanced Materials and Technology, University of Science and Technology Beijing, \\ Beijing 100083, China \\ ${ }^{2}$ Key Laboratory for Corrosion and Protection of The Ministry of Education (MOE), Beijing 100083, \\ China \\ ${ }^{3}$ Beijing Advanced Innovation Center for Materials Genome Engineering, University of Science and \\ Technology Beijing, Beijing 100083, China \\ ${ }^{4}$ CCCC Tianjin Port Engineering Institute Co., Ltd., Tianjin 300222,China \\ *E-mail: dcw@ustb.edu.cn, Liuzhiyong7804@126.com
}

doi: $10.20964 / 2021.04 .02$

Received: 1 November 2020 / Accepted: 10 January 2021 / Published: 28 February 2021

This paper investigates the corrosion behavior of three commercial anodes under different temperature and dissolved oxygen through a scanning electron microscope and electrochemical test. Our results show uniform corrosion in both environments, and the current efficiency at low temperature and low oxygen are higher than that of saturated oxygen at room temperature. Microtopography reveals that intergranular corrosion is more severe under the condition of low temperature and low oxygen. The polarization curves and electrochemical impedance spectrum tests at the initial stage of erosion illustrate that the activation dissolution resistance is more significant at low temperature and low oxygen. There are varying degrees of passivation tendency, especially Al-Zn-In-Si.

Keywords: Al alloy, temperature, dissolved oxygen, electrochemical property

\section{FULL TEXT}

(C) 2021 The Authors. Published by ESG (www.electrochemsci.org). This article is an open access article distributed under the terms and conditions of the Creative Commons Attribution license (http://creativecommons.org/licenses/by/4.0/). 